\title{
Farmer Group of Cabe Bakul (Lada Katokkon) in Rantepao District, North Toraja Regency
}

\section{Kelompok Tani Cabe Bakul (Lada Katokkon) di Kecamatan Rantepao Kabupaten Toraja Utara}

\author{
A. Sry Iryani \& Agustina Deka Minggu Bali* \\ Department of Chemistry Engineering, Universitas Fajar, Indonesia
}

\begin{abstract}
Chili is one of the most important foods for traditional Indonesian food. One of the chili that has a very high Scoville rating rating from Toraja Utara and Tana Toraja is Cabe Bakul or Lada Katokkon. This chili is different from other peppers ranging from the shape that resembles a pabrika but the size is small, it is sweet taste turned hot and good smelled. . The disadvantage of this chili is the condition of chillies that have a very high water content so it is easy to rot and wrestle so that the price quickly goes down and sometimes thrown away. To avoid the problem, the team proposes to process chili into a product but does not change the taste, color and smell. This activity helps the chili farmers to process their crops into processed products that have higher economic value. There are two types of products produced are Chili powder (Bon Cabe) and sauce. Chili sauce is made there are four variants of flavors are: original, onion, terasi and fish. Through this training the farmer group partners can cultivate the harvest and its products can compete in the Toraja market and outside Toraja.
\end{abstract}

\begin{abstract}
Abstrak
Cabe merupakan salah satu makanan terpenting untuk makanan tradisional Indonesia. Salah satu cabai yang memiliki rating Scoville sangat tinggi dari Toraja Utara dan Tana Toraja adalah Cabe Bakul atau Cabe Katokkon. Cabe ini berbeda dengan cabe lainnya mulai dari bentuknya yang menyerupai pabrika namun ukurannya kecil, rasanya manis berubah menjadi panas dan harum. Kekurangan dari cabe ini adalah kondisi buah cabe yang memiliki kandungan air yang sangat tinggi sehingga mudah membusuk dan bergelut sehingga harganya cepat turun dan kadang dibuang begitu saja. Untuk menghindari masalah tersebut, tim mengusulkan untuk mengolah cabe menjadi sebuah produk namun tidak merubah rasa, warna dan baunya. Kegiatan ini membantu petani cabe mengolah hasil panennya menjadi produk olahan yang memiliki nilai ekonomi lebih tinggi. Ada dua jenis produk yang dihasilkan yaitu bubuk cabe (Bon Cabe) dan saos. Kuah sambal yang dibuat ada empat varian rasa yaitu: original, bawang, terasi dan ikan. Melalui pelatihan ini para mitra kelompok tani dapat membudidayakan hasil panen dan produknya dapat bersaing di pasar Toraja dan luar Toraja.
\end{abstract}

(C) 2021 Author(s)

Keywords: Cabe, katokkon, saos, bon cabe.

\section{Pendahuluan}

Perkembangan bisnis kuliner di tanah air dalam beberapa tahun terakhir semakin meningkat khususnya kuliner pedas. Makanan yang pedas banyak diminat di Negara Indonesia, hal ini yang menyebabkan banyak pohon cabe ditanam di

\footnotetext{
* Corresponding author:

E-mail address: deka_mb@yahoo.com (Agustina Deka Minggu Bali)
} 
wilayah Indonesia, terutama di daerah yang cocok untuk pertanian. Budidaya cabe tidak terlalu sulit, tidak mengenal musim dan dapat dipanen sewaktu-waktu sesuai dengan masa panennya. Kabupaten Toraja Utara di Sulawesi Selatan sangat terkenal hingga ke manca negara, karena memiliki kekayaan adat budaya yang unik dan pemandangan alam yang eksotik. Di samping itu, Kabupaten Toraja Utara merupakan salah satu daerah yang terkenal dengan hasil pertanian dan perkebunannya. Selain kopi komoditas primadona khas Toraja yang terkenal adalah cabe bakul atau lebih dikenal dengan nama "Cabe Katokkon". Cabe jenis ini memiliki bentuk bulat menyerupai paprika, tapinya lebih kecil dan gemuk. Ukuran normalnya sekira 3-4 cm. Lada katokkon jika masih muda akan terlihat berwarna hijau keunguan serta berwarna merah jika sudah matang nantinya. Salah satu ciri khas cabe ini adalah tingkat kepedisan yang sangat tinggi dan memiliki aroma harum yang sangat khas. Cabe kotokkon atau didalam bahasa latinnya disebut Capsicum annuum Z.rar.sinensis ini akan tumbuh di dataran tinggi, sekitar 1000 hingga 1500 meter di atas permukaan laut. Dataran tinggi seperti Toraja Utara salah satu tempat yang sangat cocok bagi cabe ini tumbuh dengan baik.

Dalam hukum permintaan dan penawaran, jumlah barang yang ditawarkan berbanding lurus dengan harga barang tersebut, sama halnya dengan komoditas cabe katokkon, pada saat panen raya drastis harganya turun drastis karena jumlah cabe melimpah sehingga petani terpaksa menjual dengan harga rendah. Amedia (2008) menyatakan, pada saat harga cabe jatuh karena panen yang melimpah dan distribusi yang kurang cepat, sebagian petani membuang hasil panennya.

Desa Limbong Kecamatan Rantepao Kabupaten Toraja Utara merupakan salah satu daerah yang mayoritas penduduknya memilik mata pencaharian sebagai petani. Salah satu hasil pertanian yang dibudidayakan di daerah ini adalah cabe katokkon (cabe bakul). Dalam setahun mereka bisa memanen 3 hingga 4 kali panen. Di desa ini ada beberapa kelompok tani yang membudidayakan cabe katokkon, yaitu kelompok tani tilengko dan kelompok tani diakonia. Kedua kelompok tani ini memiliki permasalahan yang sama dengan petani dari daerah lain. Para petani ini tidak dapat mengatasi masalah ketika panen melimpah sehingga harga cabe turun drastis. Cita rasa dan aroma khas cabe katokkon merupakan sebuah daya tarik tersendiri sehingga permintaan dari luar daerah sangat tinggi tetapi berkendala distribusi karena kondisi cabe ini cepat membusuk dapat dilihat pada gambar 2. Hal ini terjadi karena kurangnya pengetahuan dan keahlian tentang penanganan pasca panen seperti pengolahan cabe menjadi produk olahan yang bernilai tinggi dan pengemasan cabe segar. Penggunaan cabe tidak hanya untuk konsumsi segar tetapi juga diolah menjadi produk olahan seperti saus, sambal, pasta, bubuk dan obat anestesi (Hartuti dan Asgar 1994). Jika usaha pengolahan cabe dan pengemasan cabe segar menjadi produk olahan yang terus dikembangkan maka akan meningkatkan perekonomian petani cabe khususnya masyarakat di sekitarnya karena apabila usaha ini berkembang maka akan membutuhkan tenaga kerja. Diharapkan produk ini merupakan salah satu produk unggulan dari daerah ini.

\section{Permasalahan Mitra}

Berdasarkan uraian pada analisis situasi yang telah dikemukakan maka pokok persoalan utama yang dihadapi kelompok tani cabe katokkon di Toraja Utara di Desa Limbong dapat diidentifikasikan sebagai berikut:

1. Selama ini penanganan pasca panen cabe masih sangat sederhana sehingga tingkat kerusakannya sangat tinggi. Harga cabe yang fluktuatif pada saat panen melimpah harga cabe turun drastis sehingga membuat petani cemas karena mengalami kerugian, harga cabe tidak memenuhi biaya produksi. Pemasaran hasil budidaya cabe katokkon yang selama ini masih terbatas secara tradisional yaitu dijual di pasar-pasar tradisional maupun mengantar langsung kepelanggan yang merupakan pemilik rumah makan. Hal tersebut didukung dengan masa penyimpana cabe yang tidak tahan lama.

2. Petani memiliki keinginan untuk bisa meningkatkan nilai jual cabe seperti mengolah cabe menjadi produk lain yang lebih tahan lama dan memiliki nilai ekonomi yang lebih tinggi. Kendala yang dihadapi para petani dalam mengolah cabe menjadi lebih awet adalah keterbatasan ilmu pengetahuan dan teknologi yang dimiliki.

Mengacu pada identifikasi masalah di atas maka permasalahan yang ada dapat dirumuskan sebagai berikut :

1. Bagaimana Kelompok Tani Diakonia dan Tilengko di Desa Limbong Kecamatan Rantepao Toraja Utara menangani pasca panen cabe katokkon 


\section{Bagaimana Kelompok Tani Diakonia dan Tilengko di Desa Limbong Kecamatan Rantepao Toraja Utara meningkatkan nilai jual cabe lebih tinggi.}

Dengan ciri khas khas dimiliki oleh cabe katokkon sehingga menjadi primadona tersendiri bagi penikmat kuliner yang pedis. Sehingga permintaan dari luar daerah Toraja utara sangat tinggi. Akan tetapi, seperti yang dijelaskan di atas bahwa yang menjadi permasalahan utama adalah metode penanganan pasca panen. Berikut penjelasan mengenai permasalahan tersebut:

1) Kelompok Tani Diakonia dan Tilengko di Desa Limbong Kecamatan Rantepao

Toraja Utara masih minimnya pengetahuan tentang pentingnya proses penanganan pasca panen untuk menjaga kualitas cabe seperti menentukan waktu panen yang tepat untuk mendapatkan mutu produk yang baik, disortasi untuk mencegah kerusakan, proses penyimpanan agar cabe tetap segar, pengemasan untuk melindungi mutu cabe sebelum dipasarkan dan pengangkutan.

2) Kelompok Tani Diakonia dan Tilengko di Desa Limbong Kecamatan Rantepao Toraja Utara ingin mengolah cabe menjadi produk olahan seperti cabe kering, abon cabe, bubuk cabe dan saus cabe tetapi para petani berkendala pada keterbatasan ilmu pengetahuan dan teknologi pengolahan cabe katokkon.

\section{Target Luaran}

Luaran yang dihasilkan dalam bentuk produk yang berupa abon cabe, saus cabe dan cabe bubuk. Adapun spesifikasi dari produk olahan cabe adalah sebagai berikut:

a. Saus lombok

Saus cabe adalah saus yang diperoleh dari pengolahan cabe yang matang dan berkualitas baik dengan tambahan bahan-bahan lain yang digunakan sebagai bahan pembantu. Bahan-bahan tambahan yang digunakan sangat bervariasi, tetapi yang umum ditambahkan ialah garam, gula, bawang putih dan bawang merah. Saos lombok yang dibuat hanya 4 varian rasa yaitu original, terasi, bawang dan ikan teri dan 2 varian bobot kemasan yaitu 100 gram dan 250 gram Keunggulan dari abon cabe yang akan dihasilkan nantinya adalah:

- Mempunyai cita rasa yang tinggi, bervariasi dan tingkat kepedisan yang tinggi.

- Tidak menggunakan bahan pengawet dan pewarna

- Proses pembuatan higienis dan bahan yang digunakan cabe segar.

- Tahan lama jika di simpan dalam kulkas

b. Cabe bubuk

Produk yang ketiga yang akan dibuat adalah cabe bubuk. Cabe bubuk merupakan bumbu pelengkap yang dibuat dari cabe kering yang dihaluskan. Industri cabe bubuk meningkat sebanding dengan peningkaatan permintaan masyarakat. Bubuk cabe yang dibuat hanya 1 varian original dan 2 varian bobot kemasan yaitu 100 gram dan 250 gram.

- cabe yang digunakan adalah cabe pilihan yang berkualitas

- proses pengeringan dalam oven

- proses pembuatan higienis

- tahan lama

\section{Metode Pelaksanaan}

Lokasi pengabdian ini dilaksanakan di desa Limbong Kecamatan Rantepao dengan jangka waktu pelaksanaan selama 8 bulan. Proses pelatihan dibagi menjadi dua yaitu pelatihan pembuatan saos Lombok hinggan pengemasan dan pelatihan pembuatan abon hingga pengemasan. 
a. Tahap Pembuatan Saos Cabe

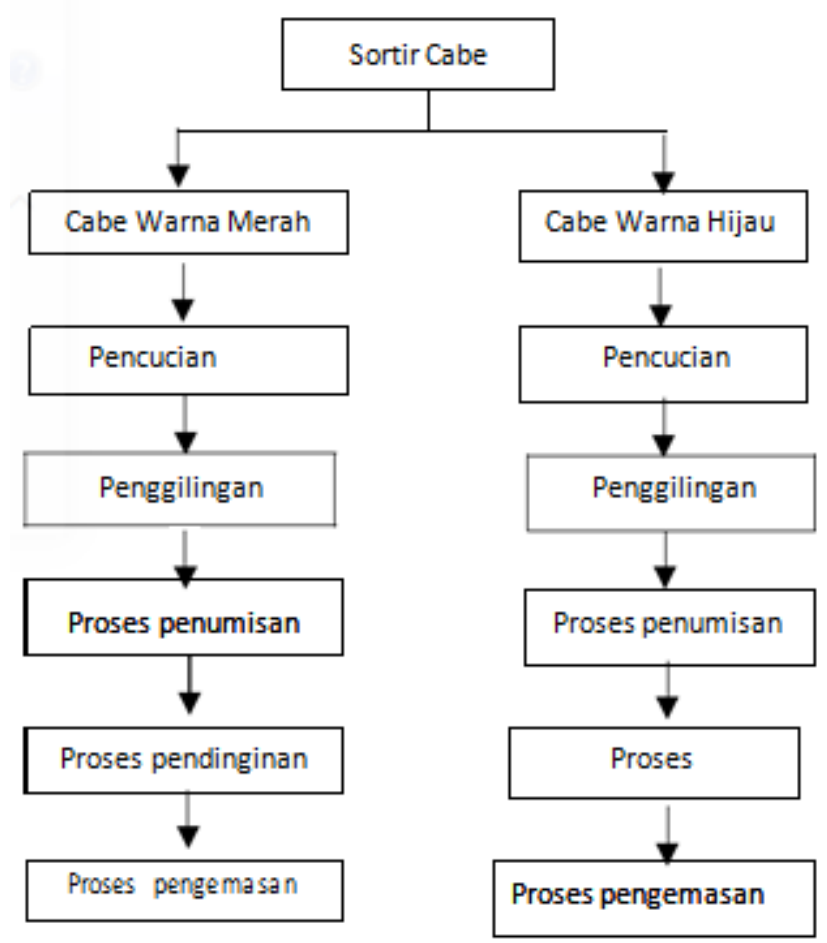

Fig. 1 Tahap pembuatan Saos Cabe

Pada Fig. 1 ditampilkan tahapan pembuatan saos cabe mulai dari penyortiran hingga pengemasan.

b. Tahap Pembuatan Bon Cabe

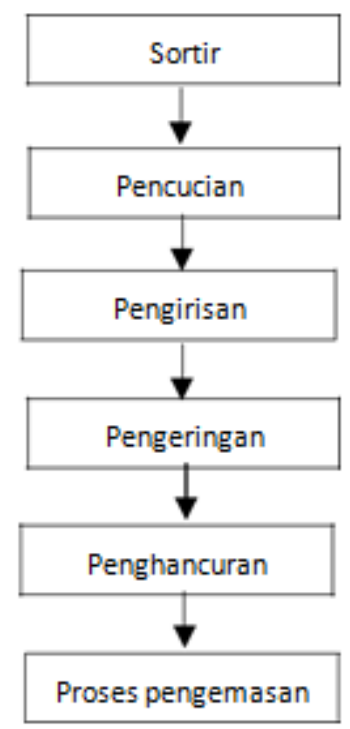

Fig. 2 Tahap pembuatan Bon Cabe

Pada gambar 2 ditampilkan tahapan pembuatan bon cabe mulai dari penyortiran hingga pengemasan. 


\section{Hasil yang dicapai}

Kegiatan pengabdian masyarakat (IbM) untuk membantu petani cabe katokkon khususnya mengolah cabe menjadi produk olahan lainnya untuk menghindari kerugian karena cabe cepat membusuk tahun 2017 dalam pelaksanaannya terdapat di lokasi Desa/Lembang Limbong Kecamatan Rantepao. Dalam desa tersebut terdapat dua kelompok tani yaitu kelompok Tani Tilengko dan Kelompok Tani Diakonia.

Proses pembuatan bon cabe dan saos cabe:

\section{1) Bon cabe}

a. Proses Sortir

Pada Proses pembuatan bon cabe, proses penyortiran dibutuhkan karena dapat cabe yang digunakan tidak semua berwarna merah dan menghindari pencampuran cabe yang bebas dari ulat dengan yang berulat.

b. Proses pencucian dan pengirisan

Proses pencucian dilakukan sebelum diiris tipis-tipis. Fungsi dari proses pengirisan adalah agar cabe cepat kering merata saat dilakukan proses pengeringan

c. Proses pengeringan menggunakan oven.

Proses ini merupakan salah satu penentu kualitas produk karena jika cabe gosong akan berpengaruh pada warna produk yang dihasilkan.

d. Proses penggilingan menggunakan blender.

Proses selanjutnya adalah proses penggilingan. Pada proses ini digunakan blender sebagai alat untuk mengguling cabe. Yang perlu diperhatikan adalah sebelum digiling Cabe harus benar-benar kering, apabila masih basah cabe tidak akan halus.

Untuk langkah langkah pembuatan bon Cabe dapat dilihat pada fig. 3 .

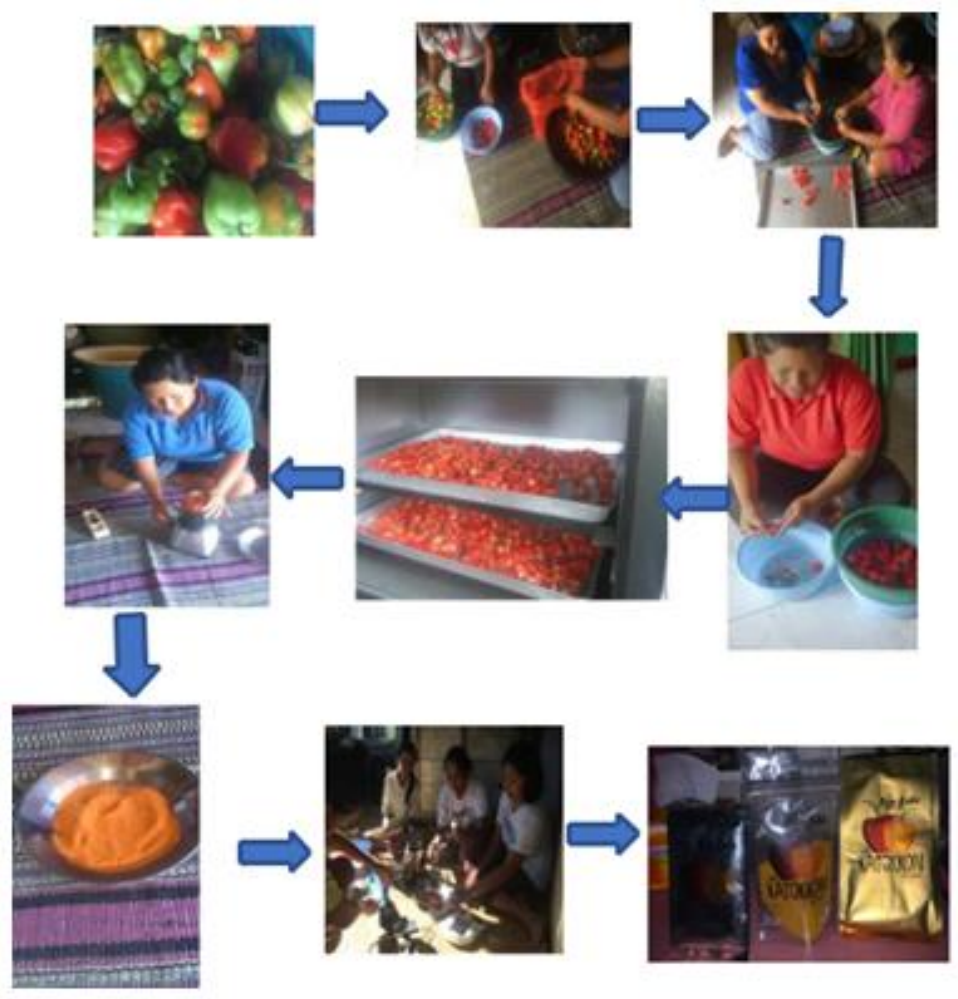

Fig. 3. Langkah pembuatan bon cabe 


\section{2) Saos Cabe}

Pembuatan Saos cabe dilakukan hamper sama dengan pembuatan bon cabe yaitu proses sortir, pencucian, penghalusan menggunakan belender. Yang membedakan bon Cabe melalui proses pengeringa sementara saos melalui proses penumisan dan penambahan rasa seperti penambahan terasi, ikan teri dan bawang. Proses pembuatan saos dapat dilihat pada fig. 4.

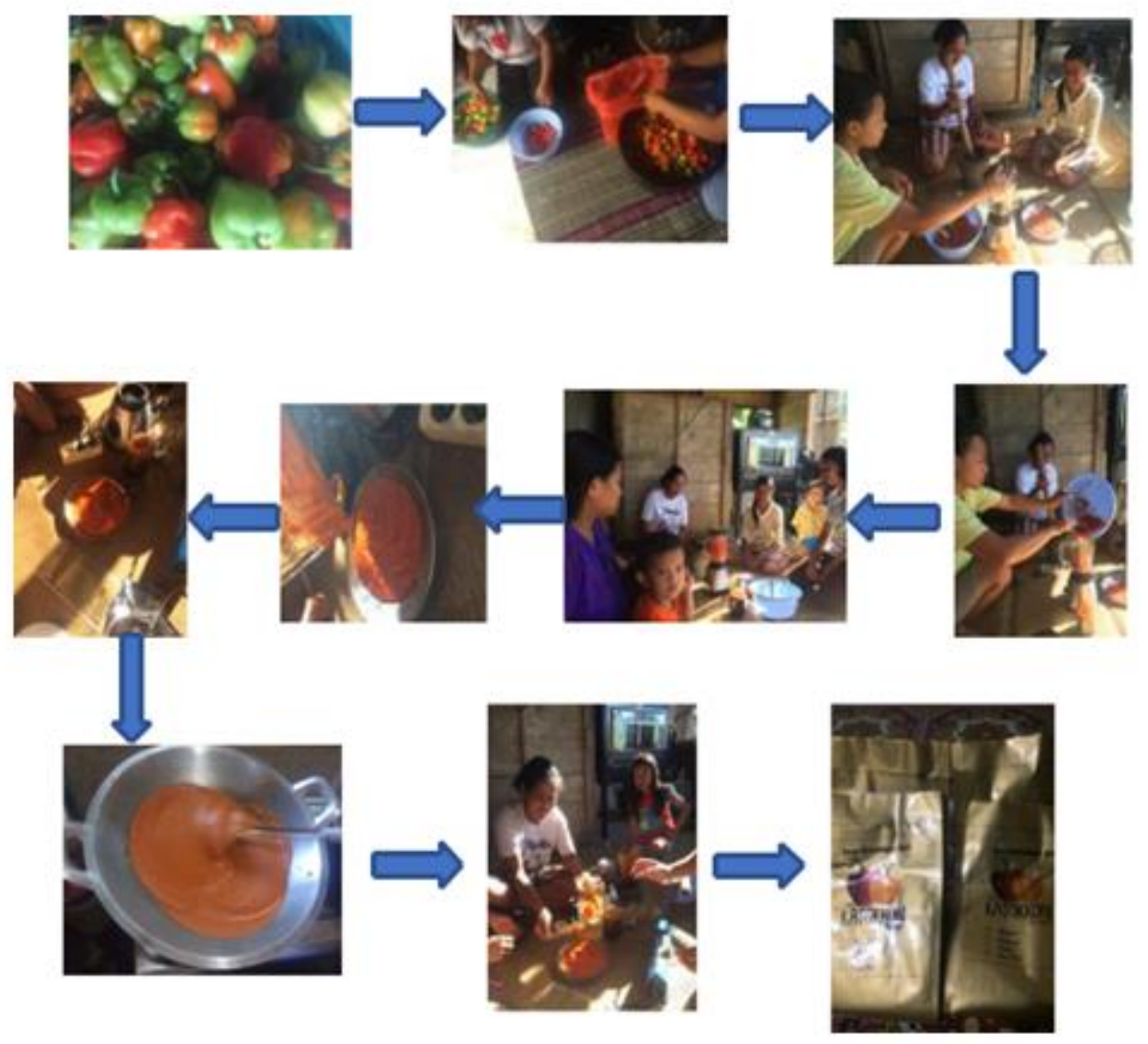

Fig. 4. Langkah pembuatan Saos Cabe Katokkon

\section{Sosialisasi dan Pelatihan}

Dalam kegiatan sosialisasi dan pelatihan yang pertama dilakukan adalah Bersama-sama tim dan mitra merakit alatalat yang digunakan. Setelah melalui perakitan dilanjutkan dengan pelatihan menggunakan alat karena alat yang digunakan termasuk baru buat mereka sehingga membutuhkan waktu untuk mengenal dan belajar menggunakan alat tersebut terutama penggunaan oven gas. Proses pelatihan dilakukan di dua tempat yaitu dilokasi kelompok tani Tilengko dan lokasi kelompok tani Diakonia yang berada di Desa Limbong Kecamatan Rantepao Kabupaten Toraja Utara.

\section{a. Lokasi pertama IbM (Kelompok Tani Tilengko)}

Kegiatan sosialisasi dan pelatihan pengolahan Cabe Katokkon menjadi bon cabe dan saos dihadiri oleh anggota kelompok Tani Tilengko beserta beberapa ibu-ibu rumah tangga yang berada disekitar Kelompok Tani Tilengko. Kegiatan dimulai dengan penyiapan bahan bon cabe dan saos cabe berupa Cake Katokkon yang telah disortir dan dicuci, tomat, garam, minyak, ikan teri yang sudah digoreng, terasi terlah dibakar, bawang goreng. Setelah bahan 
tersedia kemudian bahan untuk cabe diiris tipis-tipis untuk dikeringkan sementara cabe untuk diolah menjadi saos ditumbuk sebelum diblender hal ini dapat dilihat pada fig. 5 .
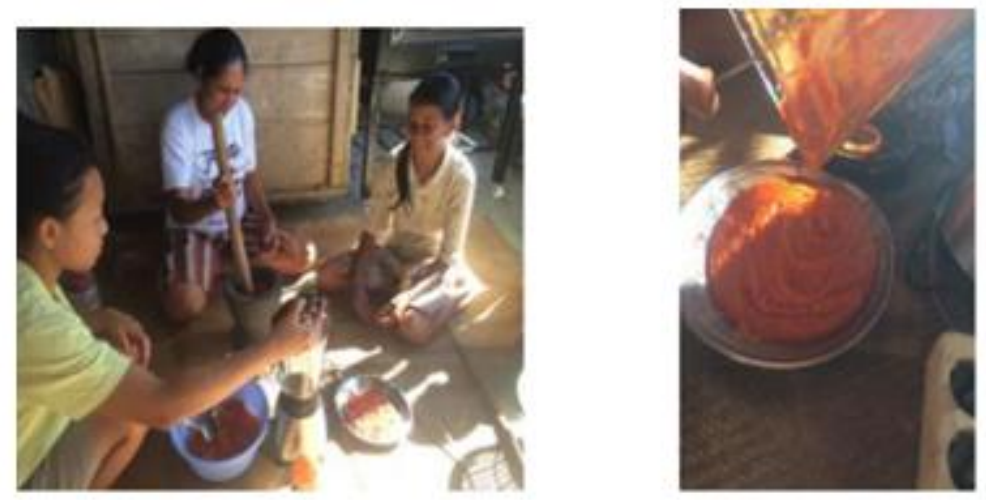

Fig. 5 Situasi saat melakukan proses penumbukan dan penggilingan cabe untuk dibuat saos

Seperti yang terdapat pada gambar 6 bahan yang sudah dibender kemudian ditumis menggunakan minyak, pada penambahan rasa dilakukan sebelum proses penumisan. Setelah proses penumisan selesai saos didinginkan kemudian dikemas.
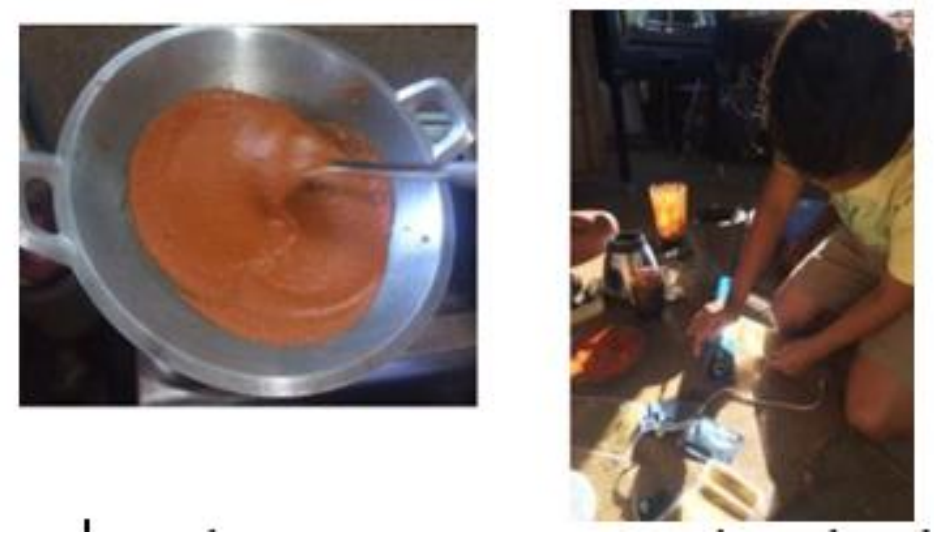

Fig. 6 Proses menumis cabe dan pengemasan saos.

Proses pengemasan menggunaan sealer dan bahan pengemas menggunakan aluminium foil. Khusus untuk saos karena menggunakan 4 varian jadi setelah melakukan pengemasan ditandai dengan memberikan tanda centak pada label yang tertera pada kemasan menggunakan spidol seperti yang terlihat pada Fig. 7 .

Untuk pembuatan bon cabe setelah melakukan pengirisan dilanjutkan dengan pengeringan menggunakan oven. Cabe yang telah kering diblender sampai halus atau menjadi bubuk.

\section{b. Lokasi kedua IbM (Kelompok Tani Diakonia)}

Kegiatan sosialisasi dan pelatihan pengolahan Cabe Katokkon menjadi bon cabe dan saos dihadiri oleh anggota kelompok Tani Diakonia beserta beberapa ibu-ibu rumah tangga yang berada disekitar Kelompok Tani Diakonia dan beberapa tokoh masyarakat dan pemerintah setempat. Kegiatan dimulai dengan penyiapan bahan bon cabe dan saos cabe berupa Cake Katokkon yang telah disortir dan dicuci, tomat, garam, minyak, ikan teri yang sudah digoreng, terasi terlah dibakar, bawang goreng. Setelah bahan tersedia kemudian bahan untuk cabe diiris tipis-tipis untuk dikeringkan sementara cabe untuk diolah menjadi saos ditumbuk sebelum diblender. Cabe yang benar-benar kering diblender hingga halus. 
Pada fig. 8 dilakukan proses pengirisan/pemotongan dilakukan untuk mempercepat proses pengeringan dan cabe juga akan kering merata.
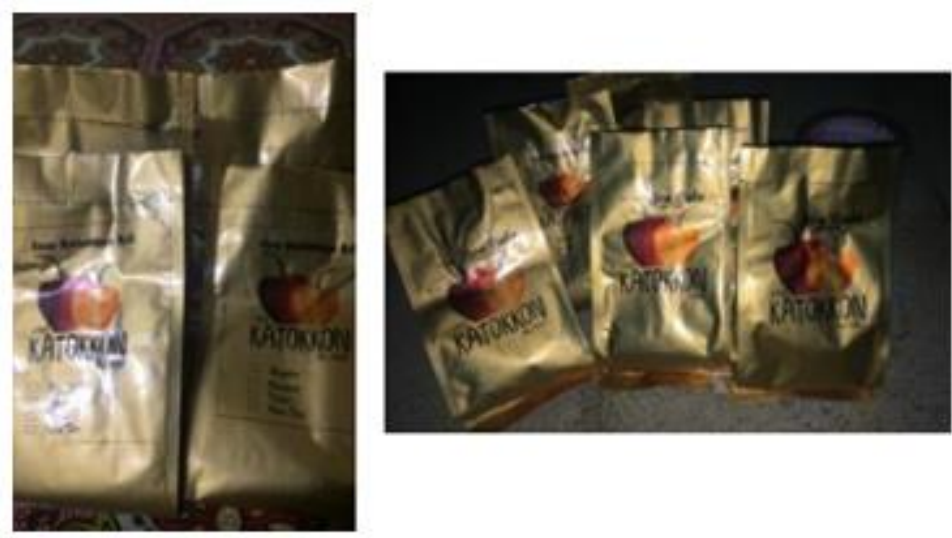

Fig. 7 Produk yang dihasilkan berupa bon cabe dan saos cabe empat varian.
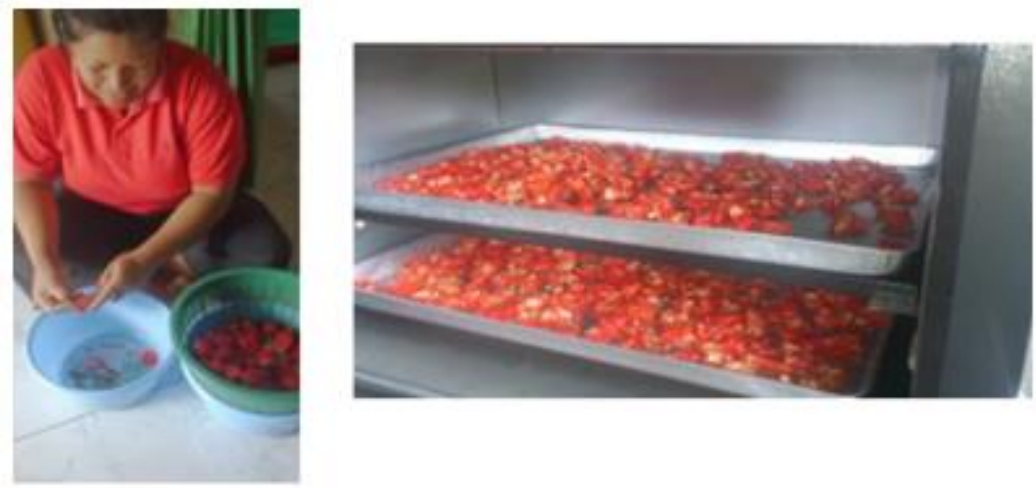

Fig. 8 Proses pengirisan dilanjutkan dengan pengovenan.

Pada proses penggilingan cabe seperti pada fig. 9 dipastikan cabe harus benar-benar kering sehingga saat proses penggilingan cabe jadi bubuk tidak melengket. Apabila proses penggilingan berlangsung ternyata cabe masih lembab maka cabe bisa dikeringkan kembali kemudian diblender ulang.
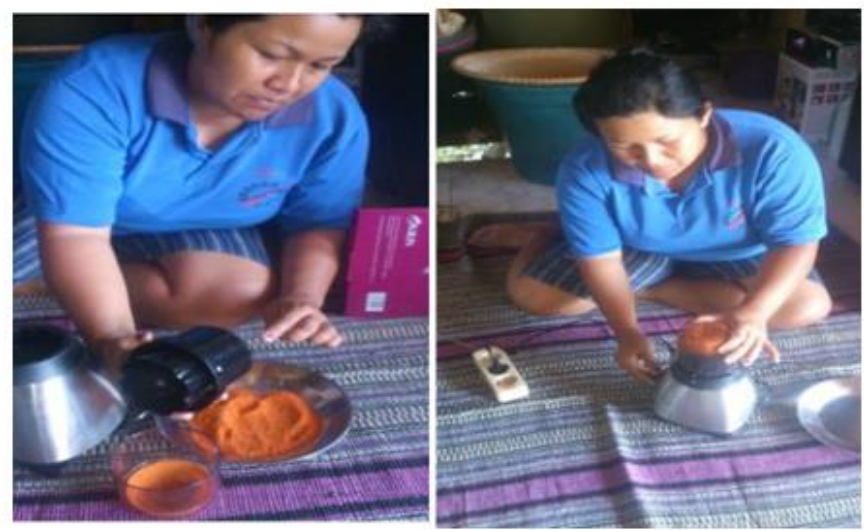

Fig. 9 Proses penggilingan cabe untuk bon cabe. 


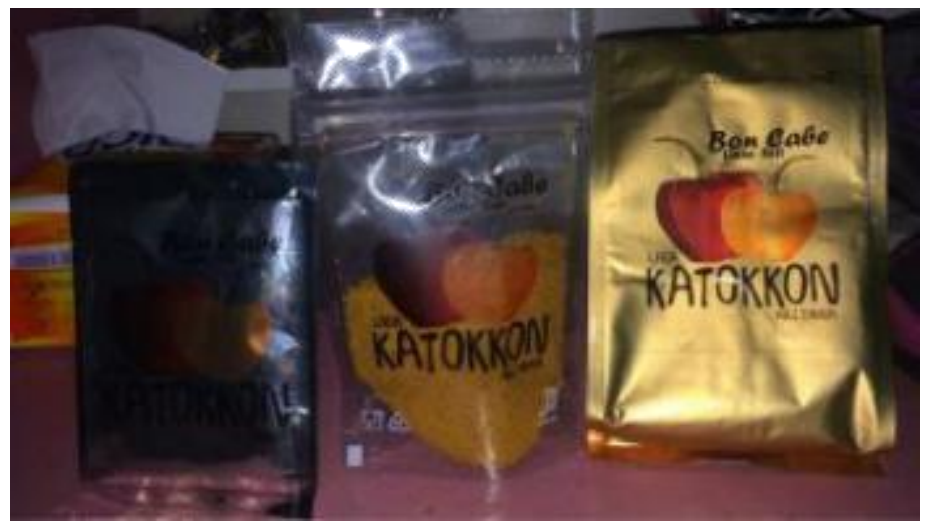

Fig. 10 Produk yang dihasilkan berupa bon cabe

Pengemasan menggunakan alluminium foil kemudian dipres untuk menjaga produk agar tahan lama.

\section{Kesimpulan dan Saran}

\section{a. Kesimpulan}

Kegiatan pengabdian yang dilakukan adalah pembuatan bon cabe dan sous cabe dan telah sosialisasi pelatihan kepada mitra dan dilanjutkan kepada masyarakat sekitar. Dari hasil pembuatan produk ini masyarakat mengembangkan pembuatan sous menggunakan cabe dan tomat saat produk melimpah dan tidak kuatir hasil panen mereka akan membusuk. Produk sous bisa dimodifikasi menjadi rasa lain seperti rasa terasi dan bawang serta dapat menbuat saos ikan teri. Sous yang dihasilkan tidak merubah rasa, warna dan bau sehingga tidak membutuhkan perisai dan pewarna makanana. Begitu pun dengan bon cabe yang dihasilkan tidak membutuhkan pewarna makanan.

\section{b. Saran}

Hasil saos cabe yang dihasilkan masih harus disimpan dalam kulkas karena tidak menggunakan pengawet makanan. Karena kondisi ini dibutuhkan riset untuk menjaga kondisi saus agar awet seperti dilakukan metode ozonisasi. Sebaiknya cabe untuk bon cabe sebelum penggilingan kondisi cabe harus dalam keadaan sangat kering agar saat penggilingan tidak lengket. Saat pengeringan khususnya menggunakan oven diperhatikan kondisi cabe jangan sampai warna cabe hangus. Apabila hangus dapat merusak warna dan rasa.

\section{References}

Amedia Pustaka. 2008. Panduan Lengkap Budi Daya dan Bisnis Cabai. Jakarta: Amedia Pustaka.

Ameriana, M., W. Adiyoga, dan L. Setiawati. 1998. Pola konsumsi dan selera konsumsi cabai dan kentang tingkat lembaga. Buletin Penelitian Hortikultura, 8(3): 1233- 1241.

Hartuti, N. dan A. Asgar. 1994. Pengaruh suhu pengeringan dan tebal pengirisan terbadap mutu tepung dua kultivar bawang merah. Prosiding Seminar Ilmiah Nasional Komoditas Sayuran 24 Oktober 1995. Balai Penelitian Tanaman Sayuran, Lembang.

Ripangi, A. 2012. Budidaya Cabai. Yogyakarta: Javalitera.

Tifani. K. T, 2013. Karakteristik Pengeringan Cabai Merah (Capsicum Annuum L.) Sebagai Pewarna Alami Kosmetik. Skripsi. Institut Pertanian Bogor Bogor

Tjahjadi, C dan H. Marta. 2011. Pengantar Teknologi Pangan. Bandung: Universitas Padjajaran. 